\title{
PREDICTIVE VALUE OF EARLY LONG-TERM MONITORING OF TOTAL ABSOLUTE BAND POWER (TABP) IN PREMATURE INFANTS CORRELATED TO NEUROLOGIC OUTCOME AT 24 MONTHS OF AGE
}

\author{
E.M. Schumacher ${ }^{1}$, P.G. Larsson ${ }^{2}$, R. Lindemann ${ }^{1}$, O.H. Skjeldal ${ }^{3}$, T.A. Stiris ${ }^{1}$ \\ ${ }^{1}$ Department of Pediatrics, Oslo University Hospital HF, Ulleval, ${ }^{2}$ Department of Neurology, Oslo \\ University Hospital HF, Rikshospitalet, Oslo, ${ }^{3}$ Women and Children's Clinic, Vestre Viken Hospital Trust, \\ Drammen, Norway
}

Background: Continuous long-term multichannel EEG monitoring of premature infant is feasible and could be a useful tool for detection of pathological processes and an early prediction of neurologic outcome.

Aim: To evaluate for correlations between tABP from day 1 to 3 in premature infants and their neurologic outcome at 24 months of age.

Methods: Forty one premature infants, GA 24-31 wks, were included and monitored (NicoletOne monitor) continuously for 3 days from soon after birth. The infants were divided into group 1 (GA 24-28 wks) and group 2 (GA 28-31 wks). Eight EEG electrodes were applied. tABP of all bands were analyzed. Mental and motor development was assessed by Bayley Scales of Infant Development II (BSID II) and Peabody Developmental Motor Scales (PDMS) at 24 months of age. Using standard procedures, raw scores were converted to the age-normed Mental Development Index, Psychomotor Development Index and Total Motor Quotient. These index and quotient scores have a population mean of 100 and a standard deviation of 15. The test results were ranked in normal or abnormal neurologic outcome (normal: index $\geq 85$; abnormal: index $<85)$.

Results: In group1 there was a significant lower tABP day 1-3 in infants with poor neurologic outcome (index $<85$ ) than in infants with normal outcome. The same was not seen in group 2.

Conclusion: This study shows a good correlation between low tABP during the 3 first days of life and poor neurologic outcome at 24 months of age in premature infants with $\mathrm{GA}<28$ wks. 